\title{
Ein Klarinettenkonzert von Bernhard Molique
}

Durch die großzügige Unterstützung der Württembergischen Bibliotheksgesellschaft (WBG) konnte im September eine Musikhandschrift erworben werden, die für den Bestand der Württembergischen Landesbibliothek eine beachtenswerte Bereicherung darstellt. Es handelt sich um die Partitur des Concertinos für Klarinette und Orchester in f-moll von Bernhard Molique (1802-1869). Die WBG stellte für den Erwerb 9.000 Euro zur Verfügung.

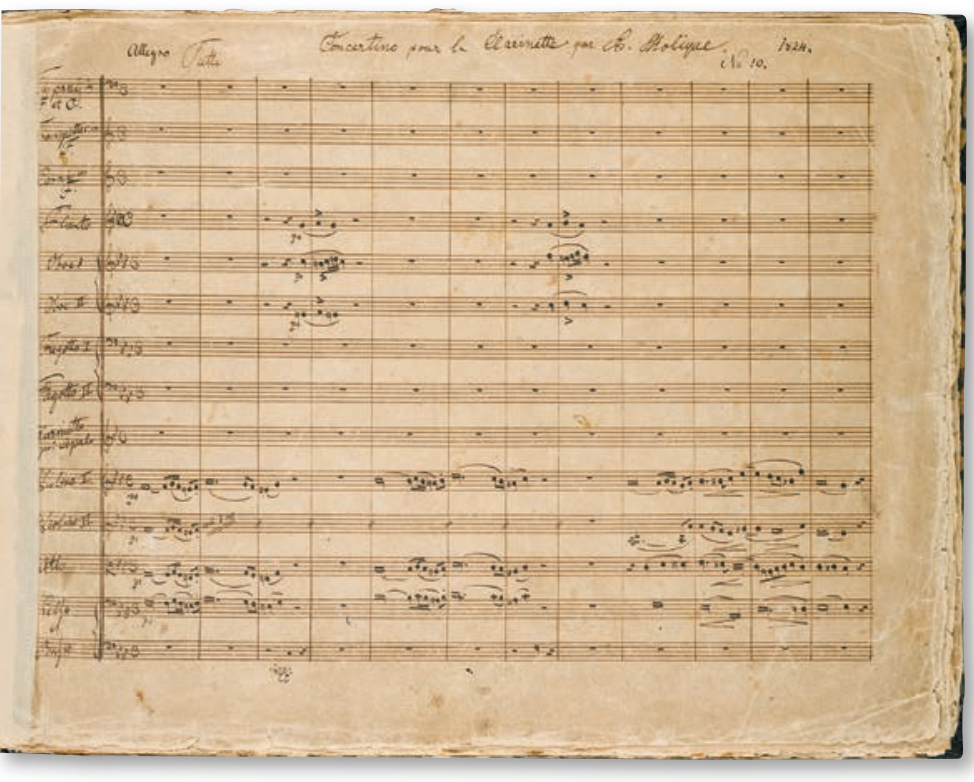

Molique erlangte vor allem durch sein Violinspiel und seine Kompositionen für Streichinstrumente Bekanntheit und spielte eine bedeutende Rolle im europäischen Musikleben seiner Zeit. Eine wichtige Station seines beruflichen Lebens war neben Wien, München und London auch Stuttgart. Am hiesigen Hoftheater war er von 1826 an über zwanzig Jahre lang als Königlicher Musikdirektor und Konzertmeister tätig.

Das aus den Sätzen Allegro - Andante - Rondo aufgebaute Concertino für Klarinette und Orchester steht ebenbürtig neben den bedeutenden konzertanten Werken für Klarinette von anderen Komponisten der romantischen Epoche wie etwa Carl Maria von Weber oder Louis Spohr. Es entstand 1824 in München, möglicherweise als Komposition für den berühmten Klarinettisten Heinrich Josef
Beermann. Seine letzten Lebensjahre verbrachte Molique wiederum in der Nähe seines früheren württembergischen Wirkungsortes, in Cannstatt bei Stuttgart.

Die Notenhandschrift, die nunmehr die Bestandssignatur Cod. mus. II $2^{\circ} 384$ trägt, umfasst 31 Blatt und ist in einen gut erhaltenen, zweifarbig gemusterten Einband aus Wachsbatikpapier gehüllt. Die Notenblätter sind zum Teil am Rand etwas mürbe, der Gesamtzustand ist aber grundsätzlich gut. Am Ende der Partitur findet sich auf S. 64 der handschriftliche Vermerk: "Finis den 6ten November 1824 Molique".

Zu Beginn finden sich die Einträge von zwei Vorbesitzern. Zum einen handelt es sich dabei um den Klarinettisten Ernst Flackus (1915-2002), der von 1938-1952 Soloklarinettist im Radio-Sinfonieorchester Stuttgart war, bevor er Professor für Klarinette an der Musikhochschule Würzburg wurde. Danach befand sich die Partitur im Besitz von Jost Michaels (1922-2004), Professor für Klarinette an der Musikhochschule Detmold, der dafür sorgte, dass das Werk - auf Grundlage der nun erworbenen Handschrift - 1970 erstmals gedruckt wurde. Die im Verlag Bärenreiter erschienene Edition ist heute vergriffen. Ein Exemplar ist jedoch Teil der Musiksammlung der WLB.

Im Bestand der WLB finden sich neben verschiedenen Druckausgaben seiner Werke handschriftlich überlieferte Kompositionen Moliques, vor allem Werke für Violine und Orchester, aber auch Lieder und Streichquartette sowie ein Flötenkonzert. Hinzu kommen ein Brief von seiner Hand sowie ein musikalischer Stammbucheintrag für seine Tochter Caroline. Ein Werk für Klarinette des verdienten Stuttgarter Künstlers suchte man hier bislang jedoch vergeblich.

Ute Becker / Kerstin Losert 